\title{
Hypercompetitiveness and Relationships: Further Implications for Romantic, Family, and Peer Relationships
}

\author{
- Hypercompetitiveness and Relationships
}

\author{
Bill Thornton ${ }^{1}$, Richard M. Ryckman ${ }^{2}$, Joel A. Gold ${ }^{2}$ \\ ${ }^{1}$ Department of Psychology, University of Southern Maine, Portland, USA; \\ ${ }^{2}$ University of Maine, Orono, USA. \\ Email: thornton@usm.maine.edu \\ Received April 28 ${ }^{\text {th }}, 2011$; revised May $31^{\text {st }}, 2011$; accepted June $28^{\text {th }}, 2011$.
}

\begin{abstract}
Romantic relationships of hypercompetitive individuals are much more problematic with greater conflict compared to those not so hypercompetitive; however, relationship satisfaction and commitment do not covary with hypercompetitiveness (Ryckman et al., 2002). Study 1 considered whether the type of commitment matters in a romantic relationship. Indeed, hypercompetitiveness was associated positively with constraint commitment (i.e., maintaining a relationship out of concern for one's investment and other social-psychological costs associated with leaving), and was associated negatively with personal dedication commitment (i.e., interest in the relationship based on concerns for mutual benefit). Not only may the romantic relationships of hypercompetitive individuals be more problematic, other interpersonal relationships may be negatively impacted as well. Study 2 noted that hypercompetitiveness was associated positively with relationship problems involving both family members and peers; however, relationship closeness with family and friends did not vary with hypercompetitiveness. Implications of findings in both studies are considered.
\end{abstract}

Keywords: Competitiveness, Hypercompetitiveness, Relationships

\section{Introduction}

Individual differences in various personality traits have been noted to influence the nature and experiences of romantic partners and have implications for perceptions of quality of, satisfaction with, and commitment to the relationship (e.g., Hendrick, Hendrick, \& Adler, 1998; Kelly \& Conley, 1987; Rempel, Holmes, \& Zanna, 1985; Robins, Caspi, \& Moffitt, 2000; Shackleford \& Buss, 1997; Watson, Hubbard, \& Wiese, 2000). This research considered the concept of hypercompetitiveness and its relationship to various aspects of the romantic experience of adults in heterosexual relationships, as well as in the relationship with family members and peers.

Hypercompetitiveness, an indiscriminate need to compete and succeed at any cost, is a neurotic means of maintaining or enhancing one's self-worth (Horney, 1937). Further, it is characterized by hostility and aggressiveness toward others, and the tendency to be manipulative and exploitive of others, across a variety of situations. According to Horney, hypercompetitiveness is a consequence of disturbed parent-child relationships in early childhood wherein parents tend to deride, humiliate, or reject the child. This serves to undermine the child's sense of basic security and contributes to feelings of inferiority and anxiety. As a defense, a hypercompetitive orientation may develop as a neurotic means to cope with the anxiety and interpersonal threat. Not only is hypercompetitiveness expected to have a negative impact on personality and social development, but it also would be detrimental in later interpersonal relationships, romantic or otherwise.

Consistent with Horney's theory, research has shown that hypercompetitive individuals are indeed highly neurotic and that this neurotic tendency is based in anger and hostility toward others (Ross, Rausch, \& Canada, 2003). Other research has provided additional evidence that hypercompetitive individuals are indeed characteristically less psychologically healthy. For instance, they have a high need to control and dominate others, engage in manipulative impression management strategies, are authoritarian and dogmatic, are low in interpersonal trust, are not forgiving of others' transgressions, are high in destructive narcissism and Machiavellianism, are not self-actualizing, and have low self-esteem (Collier, Ryckman, Thornton, \& Gold, 2010; Dru, 2003; Ryckman, Hammer, Kaczor, \& Gold, 1990; Ryckman, Libby, van den Borne, Gold, \& Lindner, 1997; Ryckman, Thornton, \& Butler, 1994; Ryckman, Thornton, Gold, \& Burckle, 2002; Thornton, Lovley, Ryckman, \& Gold, 2009; Watson, Morris, \& Miller, 1998).

In romantic relationships among heterosexual couples, Ryckman et al. (2002) reported hypercompetitive individuals to have stronger needs to control their partner, greater mistrust and jealousy, provide little emotional support to their partner, inflict more pain on them, and have more disagreement and conflict with them. Also, following Lee's (1977) typology of love, the relationships of hypercompetitives were characterized by typically negative love styles: ludus (game playing; lack of commitment), mania (very possessive, jealous love), and pragma (practical, convenient love). More positive love styles such as eros (romantic, passionate), storge (friendship), or agape (selfless, altruistic), while not evident among hypercompetitive individuals, were more characteristic of non-hypercompetitive individuals. 
Considering that a person's personality can be expected to contribute to relationship outcomes (e.g., Robins et al., 2000), and despite the characteristically negative nature of their relationships (Ryckman et al., 2002), it was somewhat surprising that hypercompetitive individuals did not express any less satisfaction with, nor any less commitment to, their relationship compared to non-hypercompetitive individuals. In Rusbult's (1980, 1983) investment model for romantic relationships, commitment and satisfaction are presumed to depend on rewards and costs associated with the relationship, the level of "investment" in the relationship (e.g., time, effort, financial resources), and the perceived availability of alternatives to the present relationship and the comparison level of these alternatives.

Relatedly, Stanley and Markman (1992) distinguished between two types of commitment, namely, personal dedication and constraint commitment (the latter reflecting the "investment concerns" of Rusbult). Personal dedication commitment is characterized by a personal interest in wanting the relationship to continue, a desire to work to maintain and/or enhance the quality of the relationship for mutual benefit, and would involve working to benefit your partner while perhaps foregoing your own personal interests. Constraint commitment, on the other hand, reflects personal, psychological, social, cultural, or economic concerns that motivate a person to maintain a relationship independent of any sense of personal dedication to the partner or relationship. So, despite their relationship problems, hypercompetitive individuals may not have perceived any comparable or better alternative relationships to the one they had, or they may have had too much already invested in their present relationship; thus, despite higher conflict, there was no less satisfaction or commitment than that observed among those less hypercompetitive.

The present study examined further the nature of constraints that may serve to moderate the level of commitment individuals, whether hypercompetitive or not, report with regard to their romantic relationships. In addition to looking at expressed satisfaction and commitment in general, the difference between personal dedication commitment and constraint commitment (Stanley \& Markman, 1992) was considered to see whether such a distinction would covary with hypercompetitiveness.

\section{Study 1}

\section{Participants and Procedure}

Undergraduate men $(n=139)$ and women $(n=168)$ at a public university in the northeast participated in this research in exchange for extra credit in their psychology course. They completed a questionnaire set, the ostensible purpose of which was to provide for baseline data for comparison use in subsequent research. The average age of male participants was 20.73 $(S D=3.71)$ and female participants was $21.63(S D=5.98)$. Additional demographics included whether they were currently in a heterosexual relationship, the length of the current relationship (converted to weeks), and the nature of the relationship: casual (1), somewhat serious (2), serious, but not engaged (3), serious and engaged (4), married/domestic partners (5). Those who were not in a current relationship ( $n=43 ; 24$ men, 19 women) were excluded from this sample prior to data analysis.

\section{Assessment Instruments}

Romantic Experiences Scale. This valid and reliable measure of relationship experiences assesses different aspects of a person's relationship and what a person gives and receives from the relationship (Levesque, 1993). Twelve different components of relationship experience are assessed (e.g., emotional support, communication, toleration, togetherness, etc.). Following Ryckman et al. (2002), of particular importance to the present study were the two subscale assessments of relationship satisfaction (5 items; sample items include "In general, I am satisfied with our relationship" and "Our relationship is just about the best relationship I could hope to have.") and relationship commitment (7-items; sample items include "I want to spend my life with him/her" and "I expect to always love her/him."). Participants responded to individual items on a 6-point scale, strongly disagree (1) to strongly agree (6). Total scores for both satisfaction and commitment were computed by summing the items responses for each of the two subscales. The 5 -item satisfaction score could range from 5 to 30, with higher scores reflecting greater relationship satisfaction (Cronbach's alpha coefficient for the present data, $\alpha=.87$ ). The 7-item commitment score could range from 7 to 42 , with higher scores reflecting greater relationship commitment $(\alpha=.80)$.

Commitment in Relationships Scale. Stanley and Markman (1992) provide for a valid and reliable assessment of two different types of commitment in personal relationships, personal dedication and constraint commitment. Personal dedication commitment refers to the desire and intent to maintain and/or improve one's relationship for the benefit of both of the individuals involved. Sample items include "My relationship with my partner is clearly part of my future life plans" and "My relationship with my partner is more important to me than almost anything else in my life." Constraint commitment, in contrast, reflects the perceived constraints that require a person to stay in a relationship regardless of the situation and personal dedication. Sample items include "My friends would not mind if my partner and I broke up (or divorced)" (reverse-scored) and "I would lose money, or feel like money had been wasted, if my partner and I broke up (divorced)." Items were responded to using 7-point continua, strongly disagree (1) to strongly agree (7). Total scores for the 36 -item personal dedication commitment scale could range from 36 to 252 , whereas total scores for the 24-item constraint commitment scale could range from 24 to 168 ; higher scores on both were indicative of greater commitment. Internal consistency for both personal dedication and constraint commitment were quite high $(\alpha=.84$ and .75 , respectively).

Hypercompetitiveness Scale. This 26-item measure is a valid and reliable assessment of individual differences in hypercompetitive attitude orientation (Ryckman et al., 1990). Sample items are "I find myself being competitive even in situations that do not call for competition" and "I find myself turning a friendly game or activity into a serious contest or conflict." Items were responded to on a 5-point scale, strongly disagree (1) to strongly agree (5). Scores could range from 26 to 130 with a higher score indicating greater hypercompetitive orientation $(\alpha$ $=.85$ ).

Social Desirability. Reynolds' (1982) short form of the Marlowe-Crowne (1964) Social Desirability Scale was included to control for self-presentational biases. This is a 13-item measure 
intended to assess individual propensity to provide socially desirable responses (cf. Crowne \& Marlowe, 1964). Sample items include "I am always courteous, even to people who are disagreeable" and "I have never deliberately said something that hurt someone's feelings." Responses were made using a 5-point continuum, "never, or almost never, true of me" (1) to "always, or almost always, true of me" (5). Scores could range from 13 to 65 ; the higher the score, the greater the tendency for an individual to express socially desirable responses $(\alpha=.76)$.

\section{Results and Discussion}

Results indicated men and women did not differ in age or either the length and type of their relationship $(F s \leq 2.4, n s)$. Men were more hypercompetitive than women $(M \mathrm{~s}=79.98$ and $73.53), F(1,302)=15.76, p<.001$. However, general relationship satisfaction and commitment did not differ between men and women $(F \mathrm{~S}<1)$, nor were there sex differences in the more specific personal dedication and constraint commitment assessments $(F \mathrm{~S}<1.4)$. Descriptive statistics are presented in Table 1.

Although men are characteristically more hypercompetitive than women, the magnitude of correlations between hypercompetitiveness and personality assessments typically do not differ between men and women (e.g., Ryckman et al., 1990, 1994, 2002; Thornton et al., 2009). As this was the case in the present study, correlational analyses were conducted on the overall group with social desirability as a covariate to control for potential bias in self-presentation on self-report assessments. Results of these partial correlation analyses are presented in Table 2.

Consistent with the previous results of Ryckman et al. (2002), hypercompetitive individuals were no less satisfied with their relationship than non-hypercompetitives $(r=-.08)$, and indicated no difference in regard to general commitment to the relationship $(r=.03)$.

Whereas general commitment was again observed to be unrelated to hypercompetitiveness, this was not the case with consideration of Stanley and Markman's (1992) distinction between specific types of commitment. Hypercompetitiveness positively correlated with constraint commitment $(r=.27, p$ $<.001)$ and negatively correlated with dedicated commitment $(r$ $=-.29, p<.001)$. Thus, hypercompetitive individuals' commitment to a relationship appears to reflect, in part, different reasons than those who are less hypercompetitive. In particular, hypercompetitive individuals appear to be less interested in the quality of their relationship and concerns for mutual benefit and benefit of their partner than they are for maintaining the relationship because of investment concerns and other possible constraints.

Having considered romantic relationships, a subsequent study

Table 1.

Mean response (standard deviation in parentheses) for men and women (Study 1).

\begin{tabular}{cccc}
\hline & Men $(n=139)$ & Women $(n=168)$ & $F$ \\
\hline Length of Relationship (in weeks) & $20.89(9.38)$ & $23.24(21.04)$ & 2.07 \\
Type of Relationship & $2.86(1.48)$ & $73.53(14.19)$ & 2.40 \\
Hypercompetitiveness & $79.98(13.99)$ & $23.61(6.29)$ & $15.76^{*}$ \\
Relationship Satisfaction & $23.97(5.54)$ & $32.42(7.66)$ & 0.27 \\
General Relationship Commitment & $31.88(6.84)$ & $178.94(34.55)$ & 0.41 \\
Personal Dedicated Commitment & $174.14(34.97)$ & $93.47(11.11)$ & 1.39 \\
Constraint Commitment & $94.88(11.46)$ & 1.16 & \\
\hline
\end{tabular}

Note. $d f=1,302 ;{ }^{*} p<.001$

Table 2.

Partial correlation coefficients controlling for social desirability response bias (Study 1).

\begin{tabular}{lcccccc}
\hline & 2 & 3 & 4 & 5 & 6 & 7 \\
\hline 1. Length of Relationship (in weeks) & $.40^{* *}$ & .03 & $.20^{* *}$ & $.32^{* *}$ & $.31^{* *}$ & $.19^{* *}$ \\
2. Type of Relationship & - & -.07 & $.28^{* *}$ & $.38^{* *}$ & $.39^{* *}$ & $.29^{* *}$ \\
3. Hypercompetitiveness & & - & -.08 & .03 & $-.29^{* *}$ & $.27^{*}$ \\
4. Relationship Satisfaction & & & - & $.69^{* *}$ & $.68^{* *}$ & $.43^{* *}$ \\
5. Relationship Commitment & & & - & $.70^{* *}$ & $.48^{* *}$ \\
6. Personal Dedicated Commitment & & & & $-63^{* *}$ \\
7. Constraint Commitment & & & & & & \\
\hline
\end{tabular}

Note. $d f=278 ; * p<.01 ; * * p<.001$. 
was conducted to examine whether other interpersonal relationships, specifically those involving family and friends, may also be differentially related to hypercompetitiveness. In this study, relationship quality would be assessed by considering the magnitude or severity of problems indicated with one's family or peers (Hudson, 1982). It was expected that hypercompetitiveness would be associated with more negative self-reported evaluations of family and peer relationships. Since relationship commitment did not seem to be appropriate where family or peers were concerned, relationship closeness was considered instead. Relationship closeness is a more generalized kind of closeness evident, and assessed, in different types of relationships, including those with both family and friends. It is characterized by high interdependence between those involved and reflects the frequency of interactions and mutual impact or influence they have over one other (Kelley et al., 1983; Berscheid, Snyder, \& Omoto, 1989). One expectation is that the relationships with family and peers of hypercompetitive individuals would not be as close as those of non-hypercom-petitives. However, considering that there was no difference in romantic relationships with regard to general commitment, general closeness in family and peer relations may not differentially relate to hypercompetitiveness either.

\section{Study 2}

\section{Participants and Procedure}

Undergraduate men $(n=90)$ and women $(n=102)$ at a public university in the northeast participated in this research in exchange for extra credit in their psychology course. They completed a questionnaire set including the instruments below with evaluations of family and peer relationship completed in counterbalanced order. As before, the ostensible purpose of the research was to obtain baseline data for comparison purposes in subsequent research. The average age of male participants was $26.54(S D=8.25)$ and female participants was $25.67(S D=$ 7.47).

\section{Assessment Instruments}

Family Relationships. The Index of Family Relations provided a valid and reliable assessment with which to measure family relationship problems (Hudson, 1982; Husdon, Acklin, $\&$ Bartosh, 1980). This is a 25 -item scale that permits the respondent to characterize the magnitude or severity of problems that a person has in his or her relationship with family and family members and can serve as an overall measure of intra-familial stress. Sample items are "I really do not care to be around my family" and "I feel left out of my family." Items were responded to using a 5-point scale, rarely, or never (1) to most or all the time (5). Item responses were totaled and 25 subtracted from each total score, thus providing for a possible range from 0 to 100 with a higher score indicating greater family relationship problems $(\alpha=.93)$. Hudson (1982) noted that a score over 30 is indicative of a clinically significant problem in the family relationship.

Peer Relationships. The Index of Peer Relations provided for a valid and reliable assessment with which to measure relationship problems with peers (Hudson, 1982; Forte \& Green, 1994; Klein, Beltran, \& Sowers-Hoag, 1990). This is a 25 -item scale intended to measure the magnitude or severity of problems a person has with his or her peers. Sample items include "My peers seem to look down on me" and "I really feel like my peers dislike me." Items were responded to using a 5-point scale, rarely or never (1) to most or all the time (5). Item responses were totaled and 25 subtracted from each total score, thus providing for a possible range from 0 to 100 with a higher score indicating greater family relationship problems $(\alpha=94)$. Hudson (1982) noted that a score over 35 is indicative of a clinically significant problem in the relationship with peers.

Relationship Closeness. The Relationship Closeness Inventory provides for a valid and reliable assessment of the interdependence that exists between people in a relationship (Berscheid et al., 1989, 2004). An overall index of "generic" relationship closeness is comprised of three components: the frequency of interactions, the diversity of interactions, and the strength of impact or influence the other person(s) has on the respondent. Frequency of interaction reflects the time spent with the other person(s) in the past week and the opportunity it provides for interpersonal influence. Times were summed and converted to a 10-point scale with a higher value indicating greater interaction time. Diversity of interaction reflects the number of activities (e.g., prepared a meal, went to movie, recreational activity) in a 38 -item checklist that were engaged in with the other person(s) in the past week. The number of activities were summed and converted to a 10-point scale with a higher value indicating a greater number of activities. Strength of influence reflects the extent to which the other person(s) influences one's own daily behavior, decisions, and plans (e.g., how I spend my free time, what I watch on TV, how I spend my money) provided in a 34-item list. The extent of influence on each item is indicated using a 7-point scale, strongly disagree (1) to strongly agree (7). Item responses are summed and converted to a 10-point scale with a higher value indicating greater influence the other person(s) has on the individual. The three converted scores are then summed to provide for an overall relationship closeness score ranging from 3 (low) to 30 (high). This assessment was completed after both family and peer relationship evaluations with instructions for respondents to think specifically about their family members or friends, respectively, when completing the scale. Internal consistency for the three-item composite for family $(\alpha=.65)$ and friends $(\alpha=.69)$ was adequate.

Hypercompetitiveness and Social Desirability. Assessments of hypercompetitive orientation (Ryckman et al., 1990) and social desirability response bias (Reynolds, 1982) were the same as described in the previous study. Internal consistencies of each in the present study were quite adequate $(\alpha=.80$ and .74 , respectively).

\section{Results and Discussion}

Men and women did not differ in age $(F<1.5, n s)$, but men were again more hypercompetitive than women, $F(1,190)=$ $11.72, p<.001$. It was also apparent that men had a greater degree or more serious expression of problems with both family members and peer relationships than that indicated by women, $F_{\mathrm{s}}=19.51$ and 11.48 , respectively, $p \mathrm{~s}<.001$. Men also indicated having less close relationships than did women with regard to both family and friends, $F \mathrm{~s}=13.18$ and 22.17 , respectively, $p s<.001$. Descriptive statistics are presented in Table 3 . 
Table 3.

Mean response (standard deviation in parentheses) for men and women (Study 2).

\begin{tabular}{cccc}
\hline & Men $(n=90)$ & Women $(n=102)$ & $F$ \\
\hline Hypercompetitiveness & $79.98(13.99)$ & $73.53(14.19)$ & $11.71^{*}$ \\
Family Relations & $24.09(22.87)$ & $12.07(13.70)$ & $19.51^{*}$ \\
Relationship Closeness_Family & $12.71(4.72)$ & $14.38(4.81)$ & $13.18^{*}$ \\
Peer Relations & $22.13(18.24)$ & $14.10(14.33)$ & $11.48^{*}$ \\
Relationship Closeness_Peers & $13.59(4.96)$ & $15.85(4.77)$ & $22.17^{*}$ \\
\hline
\end{tabular}

Note. $d f=1,190 ;{ }^{*} p<.001$.

Despite the gender differences in hypercompetitiveness as well as family and peer relation assessments, the magnitude of correlations between hypercompetitiveness and relationship assessments did not differ between men and women. As such, partial correlational analyses were conducted on the overall group with social desirability serving as a covariate to control for potential bias in self-presentation on self-report assessments. Results are summarized in Table 4.

Hypercompetitiveness was associated positively with greater degree and severity of problematic relationships with both family $(r=.25, p<.001)$ and peers $(r=.28 ; p<.001)$. Moreover, the extent or severity of problems in relationships with family members was correlated highly with problems in peer relationships $(r=.51, p<.001)$. And, the more problematic the relationship, the less relationship closeness was evident for both family and friends, although these correlations were not of significant magnitude.

Despite difficulties in their relationships with both family and friends, hypercompetitiveness was not related to overall relationship closeness in either family or peer relationships ( $r \mathrm{~s}$ $=-.03$ and .02 , respectively). However, further examination of the specific components indicated an interesting pattern. Hypercompetitiveness was associated positively with the frequency of interactions in both family $(r=.12, p=.10)$ and friend $(r=.14, p=.05)$ relationships, whereas the diversity of such interactions did not vary ( $r \mathrm{~s}=-.02$ and .04 , respectively). In addition, hypercompetitiveness was negatively associated with the strength of impact or influence others have over the respondent's behavior and decisions in family $(r=-.13, p=.07)$ and peer $(r=-.15, p<.05)$ relations. As such, hypercompetitive individuals appear to avoid, or resist, reciprocal influence,

Table 4.

Partial correlation coefficients controlling for social desirability response bias (Study 2).

\begin{tabular}{lcccc}
\hline & 2 & 3 & 4 & 5 \\
\hline 1. Hypercompetitiveness & $.25^{*}$ & -.03 & $.28^{*}$ & .02 \\
2. Family Relations & - & -.08 & $.51^{*}$ & - \\
3. Relationship Closeness - Family & & - & - & $.44^{*}$ \\
4. Peer Relations & & & - & -.10 \\
5. Relationship Closeness-Peers & & & & - \\
\hline
\end{tabular}

Note. $d f=190 ;{ }^{*} p<.001$. preferring instead to influence others, or at least give the appearance of such. This is consistent with hypercompetitive individuals being mistrustful, controlling, manipulative, and concerned with demonstrating and maintaining personal superiority over others.

\section{General Conclusion}

The romantic relationships for hypercompetitive individuals are of lesser quality and characterized by greater conflict (Ryckman et al., 2002). While they may be no less committed to their relationship, the results of Study 1 indicate that the nature of their commitment is less psychologically healthy than that characterizing non-hypercompetitive relationships. Indeed, it appears that hypercompetitive individuals have a level of commitment to their romantic relationship that is based primarily on meeting their own selfish needs and not on any concern for satisfying the needs or mutual benefit of their partners. As such, the more their own personal needs are satisfied, the more likely they are to remain committed to the relationship and thus report relationship satisfaction. These results are consistent with prior research indicative of hypercompetitives engaging in more maladaptive behavior in their romantic relationships (e.g., Ryckman et al., 2002).

The results of Study 2 further indicate that hypercompetitive individuals have problematic relationships within other interpersonal realms as well. Specifically, hypercompetitives expressed greater discontent with, and greater problems in, relationships involving both family members and their peers. Nevertheless, relationship closeness did not differ as a function of hypercompetitiveness. Indeed, hypercompetitive individuals are in need of maintaining relationships just as those less hypercompetitive. However their need may simply reflect the same personal, selfish needs as evident in their romantic relationships and thus affords them additional opportunity in which to neurotically maintain or enhance their self-image and to assert their personal superiority and control over others.

Horney (1937) expressed concern with regard to hypercompetitiveness and observed that it was particularly evident in American culture more than 70 years ago. Hypercompetitiveness, as embodied in the "win-at-all-cost" attitude, continues to be a basic component in American life and poses a potential health problem (Briggs, 2008; Ryckman et al., 1990). Research consistently demonstrates hypercompetitiveness to be associated with a diversity of negative personality correlates as well 
as having negative implications for different interpersonal relationships. Consideration of the hypercompetitive construct in counseling could prove useful for conceptualizing the problems some may have in their relationships with others, romantic or otherwise, and efforts could be directed at effecting change with regard to specific behavioral manifestations (i.e., control, dogmatic, mistrust, jealousy, etc.) in an attempt to improve on the quality of the relationship for those involved.

\section{References}

Berscheid, E., Snyder, M., \& Omoto, A. M. (1989). The relationship closeness inventory: Assessing the closeness of interpersonal relationships. Journal of Personality and Social Psychology, 57, 792-807. doi:10.1037/0022-3514.57.5.792

Berscheid, E., Snyder, M., \& Omoto, A. M. (2004). Measuring closeness: The relationship closeness inventory (RCI) revisited. In D. J. Mashek and P. Aron (Eds.), Handbook of closeness and intimacy (pp. 81-101). Mahwah, NJ: Lawrence Erlbaum Associates.

Briggs, K. (2008). The power of forgiveness. Minneapolis, MN: Fortress Press.

Collier, S. A., Ryckman, R. M., Thornton, B., \& Gold, J. A. (2010). Competitive personality attitudes and forgiveness of others. Journal of Psychology, 144, 535-543. doi:10.1080/00223980.2010.511305

Cronbach, L. J. (1951). Coefficient alpha and the internal structure of tests. Psychometrika, 16, 297-334. doi:10.1007/BF02310555

Crowne, D. P., \& Marlowe, D. (1964). The approval motive: Studies in evaluative dependence. New York: Wiley.

Dru, V. (2003). Relationships between an ego orientation scale and a hypercompetitive scale: Their correlates with dogmatism and authoritarianism factors. Personality and Individual Differences, 35, 1509-1524. doi:10.1016/S0191-8869(02)00366-5

Forte, J. A., \& Green, R. G. (1994). The reliability and validity of the index of peer relations with a clinical and nonclinical sample of adoleslcents. Journal of Social Service Research, 19, 49-65. doi:10.1300/J079v19n01 03

Hendrick, S. S., Hendrick, C., \& Adler, N. L. (1988). Romantic relationships: Love, satisfaction, and staying together. Journal of Personality and Social Psychology, 54, 980-988. doi:10.1037/0022-3514.54.6.980

Horney, K. (1937). The neurotic personality of our time. New York: Norton.

Hudson, W. W. (1982). The clinical measurement package: A field manual. Chicago, IL: Dorsey Press.

Hudson, W. W., Acklin, J. D., \& Bartosh, J. C. (1980). Assessing discord in family relationships. Social Work Research and Abstracts, 16, 21-29.

Kelley, H. H., Berscheid, E., Christensen, A., Harvey, J. H., Huston, T. L., Levinger, G., McClintock, E., Peplau, L. A., \& Peterson, D. R. (1983). Close relationships. New York: Freeman.

Kelly, E. L., \& Conley, J. J. (1987). Personality and compatibility: A prospective analysis of marital stability and marital satisfaction. Journal of Personality and Social Psychology, 52, 27-40. doi:10.1037/0022-3514.52.1.27

Klein, W., Beltran, M., \& Sowers-Hoag, K. (1990). Validating an assessment of peer relationship problems. Journal of social Service Research, 13, 71-85. doi:10.1300/J079v13n04 05

Levesque, R. (1993). The romantic experience of adolescents in satisfying love relationships. Journal of Youth and Adolescence, 22, 219-251. doi:10.1007/BF01537790

Rempel, J. K., Holmes, J. G., \& Zanna, M. P. (1985). Trust in close relationships. Journal of Personality and Social Psychology, 49, 95-112. doi:10.1037/0022-3514.49.1.95

Reynolds, W. N. M. (1982). Development of a reliable and valid short form of the Marlowe-Crowne social desireability scale. Journal of Clinical Psychology, 38, 119-125. doi:10.1002/1097-4679(198201)38:1<119::AID-JCLP2270380118> 3.0.CO;2-

Robins, R. W., Caspi, A., \& Moffitt, T. E. (2000). Two personalities, one relationship: Both partners' personality traits shape the quality of their relationship. Journal of Personality and Social Psychology, 79 251-279. doi:10.1037/0022-3514.79.2.251

Ross, S. R., Rausch, M. K., \& Canada, K. E. (2003). Competition and cooperation in the five-factor model: Individual differences in achievement orientation. Journal of Psychology, 137, 323-337. doi: $10.1080 / 00223980309600617$

Ross, S. R., Stewart, J., Mugge, M., \& Fultz, B. (2001). The imposter phenomenon, achievement dispositions, and the five-factor model. Personality and Individual Differences, 31, 1347-1355. doi:10.1016/S0191-8869(00)00228-2

Rusbult, C. E. (1980). Commitment and satisfaction in romantic associations: A test of the investment model. Journal of Experimental Social Psychology, 16, 172-186. doi:10.1016/0022-1031(80)90007-4

Rusbult, C. E. (1983). A longitudinal test of the investment model: The development (and deterioration) of satisfaction and commitment in heterosexual involvements. Journal of Personality and Social Psychology, 45, 101-117. doi:10.1037/0022-3514.45.1.101

Ryckman, R. M., Hammer, M., Kaczor, L. M., \& Gold, J. A. (1990). Construction of a hypercompetitive attitude scale. Journal of Personality Assessment, 55, 630-639. doi:10.1207/s15327752jpa5503\&4 19

Ryckman, R. M., \& Houston, D. M. (2003). Value priorities in American and British female and male university students. Journal of Social Psychology, 143, 127-138. doi:10.1080/00224540309598435

Ryckman, R. M., Libby, C. R., van den Borne, B., Gold, J. A., \& Lindner, M. A. (1997). Values of hypercompetitive and personal development competitive individuals. Journal of Personality Assessment, 62, 84-94. doi:10.1207/s15327752jpa6201 8

Ryckman, R. M., Thornton, B., \& Butler, J. C. (1994). Personality correlates of the hypercompetitive attitude scale: Validity tests of Horney's theory of neurosis. Journal of Personality Assessment, 62, 84-94. doi:10.1207/s15327752jpa6201 8

Ryckman, R. M., Thornton, B., Gold, J. A., \& Burckle, M. A. (2002). Romantic relationships of hypercompetive individuals. Journal of Social and Clinical Psychology, 21, 517-530. doi:10.1521/jscp.21.5.517.22619

Shackkelford, T. K., \& Buss, D. M. (1997). Marital satisfaction in evolutionary psychological perspective. In R. J. Sternberg and M. Hojjat (Eds.), Satisfaction in close relationships (pp. 7-25). New York: Guilford Press

Stanley, S. M., \& Markman, H. J. (1992). Assessing commitment in personal relationships. Journal of Marriage and the Family, 54, 595-608. doi:10.2307/353245

Thornton, B., Lovley, A., Ryckman, R. M., \& Gold, J. A. (2009). Playing dumb and knowing it all: Competitive orientation and impression management strategies. Individual Differences Research, 7, 265-271.

Watson, D., Hubbard, B., \& Wiese, D. (2000). General traits of personality and affectivity as predictors of satisfaction in intimate relationships: Evidence from self- and partner-ratings. Journal of Personality, 68, 413-449. doi:10.1111/1467-6494.00102

Watson, P. J., Morris, R. J., \& Miller, L. (1998). Narcissism and the self as continuum: Correlations with assertiveeness and hypercompetitiveness. Imagination, Cognition, and Personality, 17, 249-259. 